\title{
Attribution of detected changes in streamflow using multiple working hypotheses
}

\author{
S. Harrigan ${ }^{1}$, C. Murphy ${ }^{1}$, J. Hall ${ }^{2}$, R. L. Wilby ${ }^{3}$, and J. Sweeney ${ }^{1}$ \\ ${ }^{1}$ Irish Climate Analysis and Research Units (ICARUS), Department of Geography, National University of Ireland Maynooth, \\ Maynooth, Ireland \\ ${ }^{2}$ Institute of Hydraulic Engineering and Water Resources Management, Vienna University of Technology, Vienna, Austria \\ ${ }^{3}$ Centre for Hydrological and Ecosystem Science, Department of Geography, Loughborough University, Loughborough, UK
}

Correspondence to: S. Harrigan (shaun.harrigan@nuim.ie)

Received: 25 September 2013 - Published in Hydrol. Earth Syst. Sci. Discuss.: 15 October 2013

Revised: 22 February 2014 - Accepted: 7 April 2014 - Published: 23 May 2014

\begin{abstract}
This paper revisits a widely cited study of the Boyne catchment in east Ireland that attributed greater streamflow from the mid-1970s to increased precipitation linked to a shift in the North Atlantic Oscillation. Using the method of multiple working hypotheses we explore a wider set of potential drivers of hydrological change. Rainfallrunoff models are used to reconstruct streamflow to isolate the effect of climate, taking account of both model structure and parameter uncertainty. The Mann-Kendall test for monotonic trend and Pettitt change point test are applied to explore signatures of change. Contrary to earlier work, arterial drainage and simultaneous onset of field drainage in the 1970s and early 1980s are now invoked as the predominant drivers of change in annual mean and high flows within the Boyne. However, a change in precipitation regime is also present in March, thereby amplifying the effect of drainage. This new explanation posits that multiple drivers acting simultaneously were responsible for the observed change, with the relative contribution of each driver dependant on the timescale investigated. This work demonstrates that valuable insights can be gained from a systematic application of the method of multiple working hypotheses in an effort to move towards more rigorous attribution, which is an important part of managing emerging impacts on hydrological systems.
\end{abstract}

\section{Introduction}

There has been a proliferation of studies assessing changes in observed hydrological series (whether gradual trend, abrupt change or more complex forms) at the catchment scale (e.g. Villarini et al., 2009; Burn et al., 2010; Petrone et al., 2010; Stahl et al., 2010; Hannaford and Buys, 2012; Murphy et al., 2013). While statistical detection of change is an important scientific endeavour, attribution of change (i.e. determining the most likely cause(s)) is fundamental to developing appropriate management responses and long-term adaptation strategies. In pursuit of evidence-based decision making, water managers need to not only better understand how but also why hydrological change is happening. Without rigorous attribution, detection studies can be of limited use for planning and could even lead to mal-adaptation, thereby increasing risks to society and the environment, or wasting limited economic resources.

Merz et al. (2012) claim that most studies of statistically detected change in floods fall into the category of "soft" attribution: they typically employ qualitative reasoning and/or correlation-based techniques to show consistency between changes detected and typically a single driver (e.g. climatic change) with little effort to reliably quantify the assumed cause-effect relationship, and even less effort to falsify alternative candidate drivers. In calling for increased rigour in attribution, they suggest a framework of "hard" attribution based on evidence of consistency (effect of an identified driver(s) translated into observed change), inconsistency (observed change is inconsistent with alternative drivers) and provision of a statement of confidence (strength of attribution 
statement with acknowledgment of data and methodological limitations). The authors outline many potential drivers of change that affect river systems and catchments at different scales. These range from natural and anthropogenic climate variability and change, to internal human-induced modifications within the catchment system (such as urbanisation and deforestation) to disturbances to the river channel itself from river training or reduction of channel length. Since multiple factors may be acting in parallel and interact with each other, they call for approaches that investigate multiple, rather than single, drivers of change.

Without considering the entire signal of change, some studies have begun to include a wider set of factors for attribution. For example, Jia et al. (2012) employed a fingerprintbased method to attribute observed changes in water resource amounts in the Hai catchment, China, to local human activity, rather than climate variability. Vorogushyn and Merz (2013) showed that an important contribution to detected increasing trends in observed flood time series along the Rhine is attributable to extensive river training. Fenicia et al. (2009) used a rainfall-runoff modelling approach to re-examine an anomalous model overestimation in the river Meuse rainfall-runoff behaviour between 1930 and 1965 and hypothesised that land-use and land-management changes rather than climate change (as suggested by previous studies) were the likely responsible drivers. Within the Upper Mississippi River basin, despite extensive evidence of landuse/land-cover change, Frans et al. (2013) attribute increases in runoff to growing regional precipitation, amplified by artificial field drainage. Hundecha and Merz (2012) use ensemble simulations to assess the relative importance of meteorological drivers in accounting for detected changes in flooding for catchments in Germany, showing that detected trends in extreme streamflow were attributable to changes in precipitation.

Hydrological modelling-based approaches have been widely used for change detection and attribution (e.g. Schreider et al., 2002; Andréassian et al., 2003; Seibert and McDonnell, 2010; Gebrehiwot et al., 2013). The creation of a virtual control catchment (e.g. Andréassian et al., 2003) is possible by calibrating rainfall-runoff models before a known internal disturbance (such as forest cover change, urbanisation, river engineering, dam construction) to reconstruct streamflow throughout the period of interest, driven by observed climate inputs as if the internal change had not occurred. Any divergence between reconstructed and observed streamflow can then be attributed to an internal disturbance rather than a change in climate, with the premise that the model(s) fully capture catchment behaviour. Use of models to isolate internal disturbances from external climate-driven changes can help to decipher the nature of change and therefore contribute to a better understanding of processes of change.
Most attribution studies to date have been limited to one or two drivers of change. In moving towards more rigorous attribution through systematic examination of known drivers in explaining the full signal of change, the method of multiple working hypotheses (MMWH) offers an established approach in which to develop and test hypotheses of change (Chamberlin, 1890). MMWH involves development, prior to the analysis, of several hypotheses that might explain the phenomenon being observed, while explicitly recognising the possibility that more than one hypothesis may be simultaneously valid. This increases the likelihood of uncovering potential interactions and synergies among hypotheses. The method requires an open-minded assessment of plausible explanations of the phenomenon under study, including the possibility that none are correct and that some new explanation may emerge given further research and/or additional data. Many studies have highlighted the utility of MMWH (e.g. Platt, 1964; Raup and Chamberlin, 1995; Elliott and Brook, 2007), and in the context of hydrological change we assert that it has the potential to provide a more systematic approach to attribution.

In practical application of MMWH there will be a certain level of subjectivity in the initial selection of hypotheses as well as data limitations in quantitatively assessing drivers. However, these drawbacks should not discourage attempts to assess a larger set of potential causes of hydrological change as knowledge of drivers can be reasonably gained in many cases. Additionally, MMWH is more systematic and holistic than traditional approaches to attribution where the consideration of a single (or limited) driver of change can lead to confirmation bias. Nonetheless, only a few studies in hydrology have employed MMWH, such as Clark et al. (2011), who advocates MMWH in attaining more scientifically defensible and operationally reliable hydrological models.

In combining MMWH and the framework proposed by Merz et al. (2012), this paper revisits an earlier study that attributed an abrupt change (change point) in daily streamflow records of the Boyne catchment in east Ireland to climatic change (Kiely, 1999). Using flow series derived from the gauging station at Slane Castle for 1941-1995, Kiely (1999) found a statistically significant upward change point (increase in flow after change point) in annual (1978, $p=0.004)$ (Fig. 1) and March (1976, $p=0.001)$ mean flows. Additionally, on a national scale an increase in March, October and annual precipitation was found to occur after 1975, most noticeably in west Ireland (Kiely, 1999). The change point in both variables was attributed to a shift to more positive phase of the North Atlantic Oscillation (NAO) since the mid1970s, resulting in stronger midlatitude westerlies, with increased precipitation over Ireland, and higher mean annual and March streamflow.

Here the single-driver analysis of Kiely (1999) is extended by investigating multiple factors of external and internal change within the Boyne catchment. Using MMWH a preliminary assessment of consistency with the observed change 


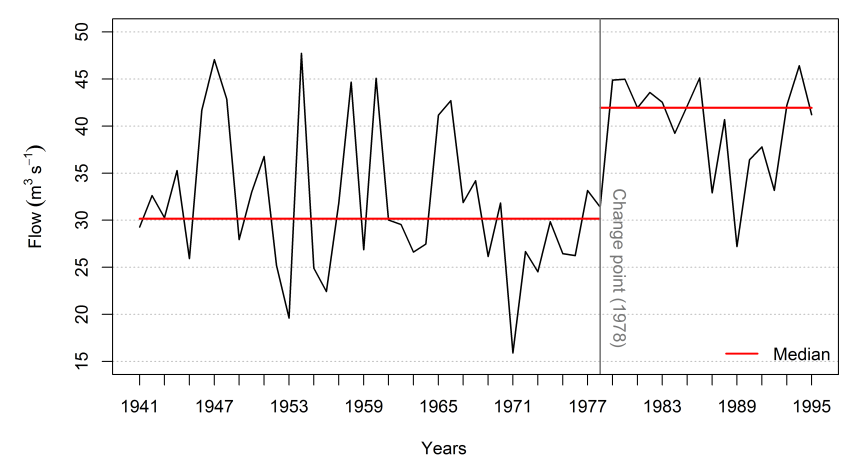

Figure 1. Observed annual mean flows in the Boyne for 1941-1995. Solid red line is the median of the period before and after the 1978 change point detected by Kiely (1999).

point is undertaken based on process understanding, available information on potential drivers and meta-data. From this screening, hypotheses about the causes of change are formulated and assessed in more detail. To isolate hypothesised internal and external (climatic) drivers of change, streamflow is reconstructed using a suite of conceptual rainfallrunoff (CRR) models. Statistical tests for evidence of both monotonic trends and change points are employed to explore signatures of change from hypothesised drivers using a comparative analysis between reconstructed and observed streamflow and precipitation. Accordingly, Sect. 2 provides detail on the case study catchment and presents a preliminary assessment of the potential drivers of change within the Boyne using MMWH. Section 3 outlines the methods and data used to decipher the nature of change. The results are presented in Sect. 4 and discussed in Sect. 5 in light of advancing more rigorous attribution within the discipline before key conclusions and suggestions for further research are offered in Sect. 6.

\section{Study area and hypotheses of hydrological change}

\subsection{The Boyne catchment}

The study area is the Boyne catchment at Slane Castle streamflow gauging station (lat $53.706870^{\circ} \mathrm{N}$, long $6.562389^{\circ} \mathrm{W}$ ) (Fig. 2). The Boyne is located in east Ireland and has annual average total precipitation of $897 \mathrm{~mm}(1952-$ 2009). The catchment area is $2460 \mathrm{~km}^{2}$ and main channel length is $94 \mathrm{~km}$. Topography is predominantly flat to undulating lowland with elevation ranging between 16 and $338 \mathrm{~m}$. Soil and land-use data were obtained from the Irish Environmental Protection Agency (EPA). Land-use was calculated using the 2006 European Union Coordination of Information on the Environment (CORINE) data set and consists mainly of agricultural pastures (87\%) with approximately $1.5 \%$ forest and urban area. The catchment is classified as "essentially rural" (Institute of Hydrology, 1999). More than $35 \%$ of the

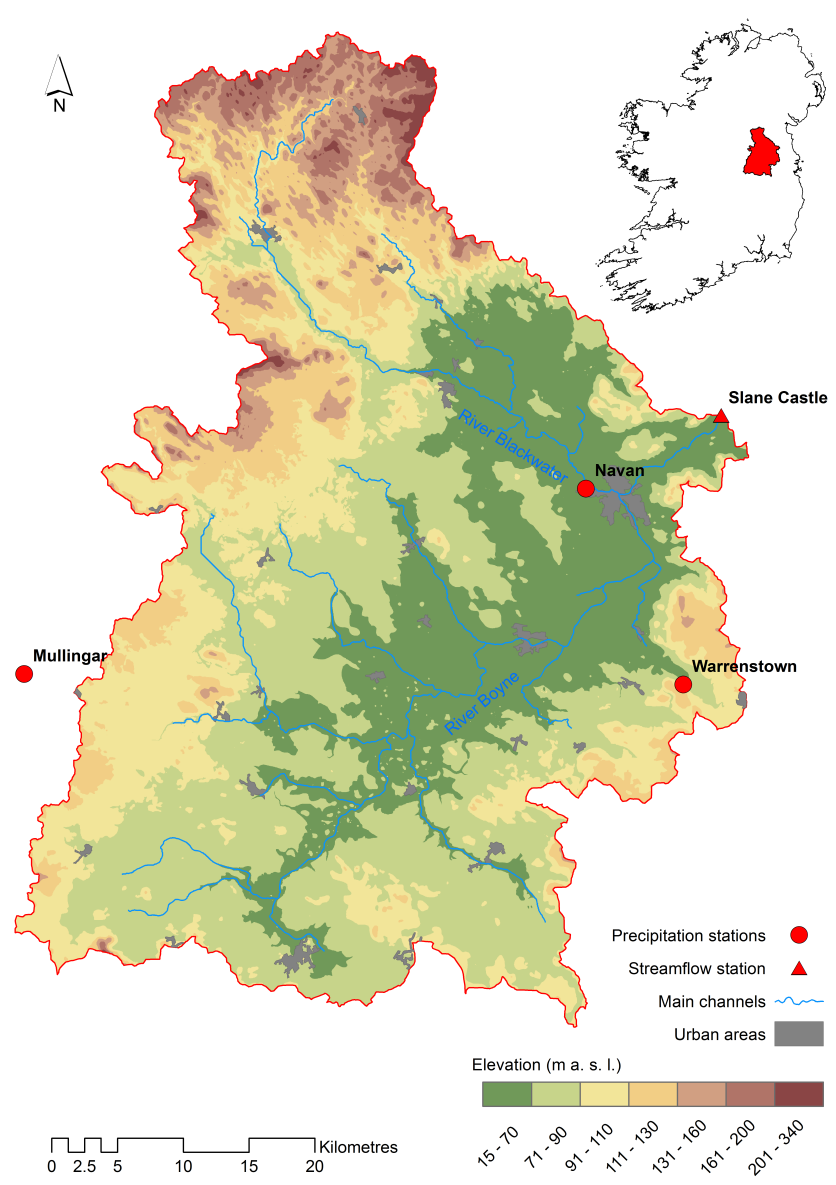

Figure 2. Boyne catchment showing major urban areas, streamflow and precipitation stations.

Boyne is comprised of poorly drained soils (mainly basin peats and gleys).

\subsection{Overview of potential drivers of hydrological change}

The observed streamflow behaviour in the Boyne - a large upward change point - narrows the choice of plausible drivers. Most land-use changes develop gradually over decades to centuries, whereas alterations to the river channel by engineering works would be visible as an abrupt change (Merz et al., 2012). Climate variables can also have an effect across multiple timescales. Anthropogenic climate change is expected to unfold as a gradual intensification of the hydrological cycle over decadal timescales (Huntington, 2006; Durack et al., 2012), whereas recurrent patterns of largescale atmospheric variability such as the NAO can manifest as an abrupt change (Kiely, 1999). If potential drivers of change are occurring in concert and over similar timescales, then their relative contributions need to be deconstructed.

Using MMWH, possible explanations for the change points detected by Kiely (1999) were derived. Our 
11 working hypotheses (WHs) (Table 1) are based on potential internal and external (climate) drivers of change, together with combinations of drivers where potential synergies (WH 10) are apparent. There is also an acceptance that other factors not yet known/accounted for could be contributing to or counteracting change (WH 11). Each WH was subject to an assessment of consistency with the detected change based on previous literature, expert consultation and analysis of available qualitative and quantitative data. Potentially important drivers were selected for further quantitative analysis as described below.

Some hypotheses of change were relatively straightforward to reject, such as WH 2 (water abstractions/diversions), which both is inconsistent with the direction of detected change and has limited influence volumetrically on the natural flow regime. Contemporary surface water abstraction within the Boyne catchment upstream from Slane Castle, as estimated by EPA (2009), is $\sim 8 \%$ of the 1952-2009 Q95 (flow equalled or exceeded for $95 \%$ of the time) and is therefore considered too insignificant to impact the natural flow regime (Bradford and Marsh, 2003). Change in potential evapotranspiration (PET) (WH 9) was also assessed using estimated PET derived for Dublin Airport, which is the closest synoptic station ( $38 \mathrm{~km}$ south-east of Slane Castle streamflow gauging station) with data covering the period of study. PET was eliminated as no statistically significant gradual or abrupt changes in annual or monthly total PET were found using the methods described in Sect. 3.3. The quality and consistency of hydrometric data at Slane Castle gauging station was examined through consultation with responsible hydrometric personnel. The station changed ownership from the Irish Electricity Supply Board (ESB) to the Office of Public Works (OPW) on 25 February 1977, which also coincided with metrication of measurements. Archived paper streamflow charts before and after 1977 were examined for inconsistencies in measurement and data collection methods along with historical and current rating curves for this station. For the period of record the gauge is deemed of high quality for high and mean flows and fair for low flows according to OPW quality ratings. The station location and measurement method (automatic gauge) have remained the same throughout. Inconsistent/poor-quality streamflow data (WH 1) were therefore ruled an unlikely explanation of the observed change point.

WH 3 to 5 (treated water discharges, urbanisation and forest cover and management change) were not selected for further analysis due to their assumed second-order influence. An increase in treated water discharges (WH 3 ) is known to have occurred around the mid-1970s due to discharge of groundwater into the River Boyne from a zinc and lead mine $2 \mathrm{~km}$ west of the town of Navan. The contribution to flow is limited to a dilution rate of $1 \%$ (EPA, 2012) and hence can be effectively ruled out as having a major influence on streamflow.

The impact of land-use changes are difficult to assess at the scale of the Boyne catchment. In spite of this, it is a local phenomenon, so the impact is assumed to decrease with increasing catchment size (Blöschl et al., 2007). However, it is important to consider the position of land-use change within the catchment as well as total extent of disturbances. The town of Navan (Fig. 2) is the largest in the catchment $\left(9.13 \mathrm{~km}^{2}\right.$ in 2006) and is situated $10 \mathrm{~km}$ upstream of the Slane Castle gauging station. While the population of $\mathrm{Na}-$ van urban area decreased slightly (5.6\%) from 4367 people between 1971 and 1981, the population immediately surrounding the town centre almost doubled from 5907 to 11136 people over the same period (Meath County Council, 2009). Navan also experienced a similar expansion in population between 1996 and 2002, but streamflow at Slane Castle shows no evidence of change during this period. Hence, an increase in population leading to likely urban expansion in the 1970s was deduced not to have had an important influence, although it is acknowledged that the effects of the two periods of urban expansion might be different with regard to their influences on the hydrological system. Forest cover (WH 5) accounts for only $\sim 1.5 \%$ of catchment landuse (in 2006), with change in management practices unlikely to cause a magnitude of change in streamflow consistent with that detected.

\subsubsection{Arterial and field drainage}

Both WH 6 (arterial drainage) and WH 7 (agricultural landuse and management change) were identified as plausible drivers of change. Arterial drainage (WH 6) has been widely installed in Ireland and involved the artificial widening and deepening of main river channels and important tributaries to improve their discharge conveyance. O'Kelly (1955) noted that following arterial works peak flows were raised to about 3 times pre-drainage values and that both the time to peak and the duration of flood hydrographs were greatly shortened following implementation in the adjacent Brosna catchment. Similar responses in flood peaks have been reported elsewhere (e.g. Bree and Cunnane, 1979; Bailey and Bree, 1981; Lynn, 1981). Likewise, Wilcock and Wilcock (1995) examined the impacts of arterial drainage on the river Maine in Northern Ireland and found systematic increases in high flows. Similarly, Bhattarai and O'Connor (2004), studying the Brosna catchment with the benefit of additional data, confirm the effects of arterial drainage reported by previous research.

The Boyne catchment has experienced widespread arterial drainage, with over $60 \%$ of the river network affected during the period 1969-1986 (OPW, 2014). The Boyne scheme represents the largest investment in arterial drainage in Ireland at a cost of 8.6 million Irish Pounds at the time (equivalent of EUR 10.9 million without accounting for inflation) and employed 1000 people at peak (OPW arterial drainage archives). Figure 3 shows the extent and timing of completion of arterial drainage works and the cumulative length of network excavated for major watercourses in the catchment 


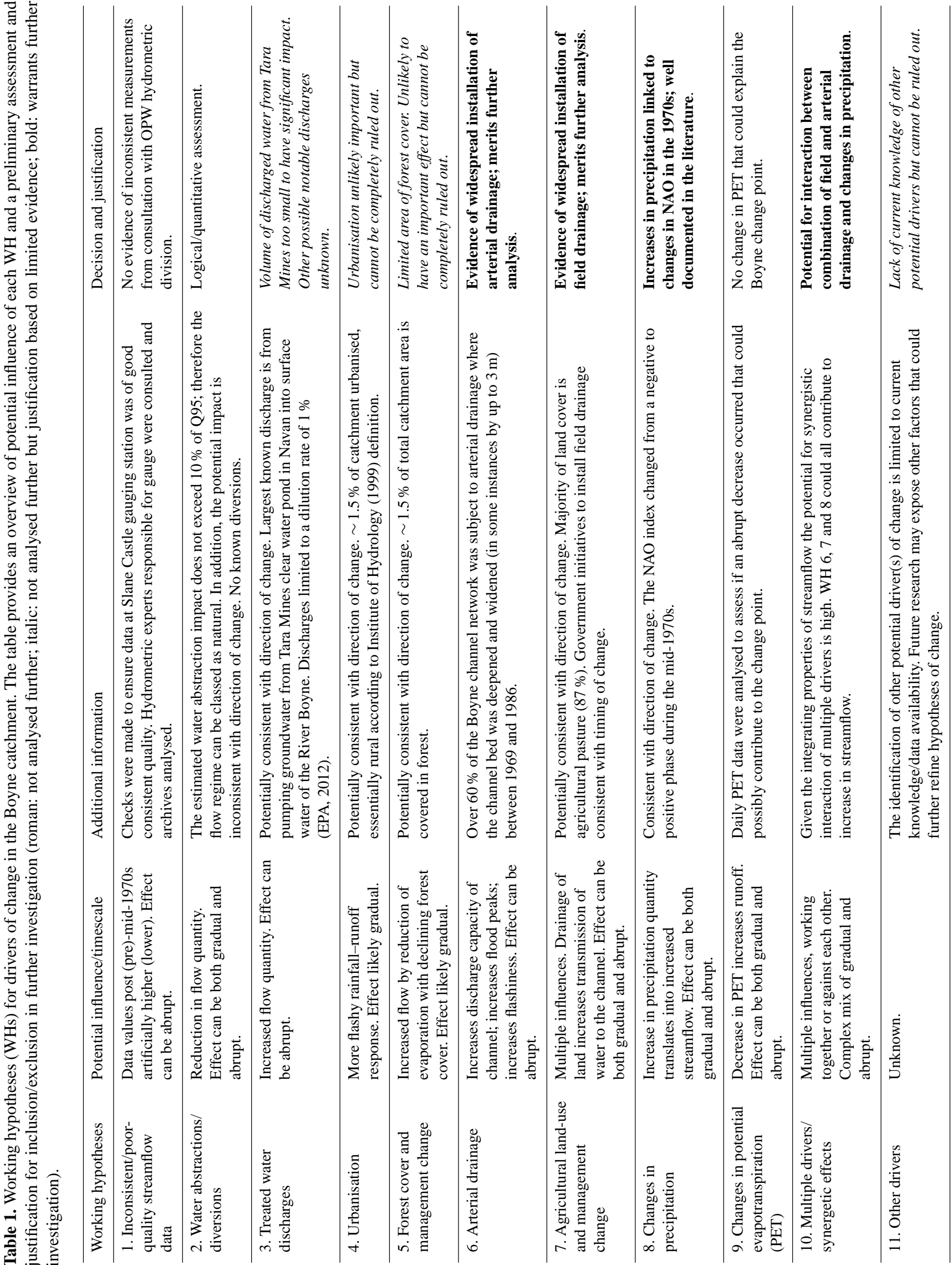




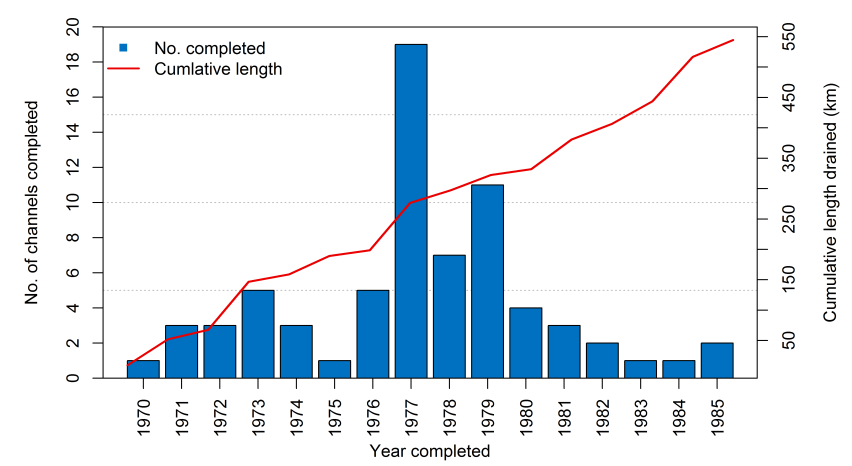

Figure 3. Number of major watercourses per year in which arterial drainage was completed in the Boyne. The cumulative length $(\mathrm{km})$ completed is shown by the red line.

based on information derived from hard-copy archives held by OPW. Most works on channels were completed between 1977 and 1979 with large increases in the length of channel $(\mathrm{km})$ in which drainage works were completed in 1973, 1977 and when the works at the largest tributary (the Blackwater) and the Boyne main channel were completed in 1983 and 1984 respectively.

The most important agricultural land-use and management change (WH 7) during the late 1970s and early 1980s was the implementation of field drainage. Field drainage involves the installation of pipes and ditches to remove surplus water from waterlogged agricultural lands resulting in reduced transmission time of water to river channels. Little research has been reported in Ireland on the impact of field drainage on hydrological response; however, Burdon (1986) notes that field drainage appreciably increases winter and spring flows (wetter seasons) from drained lands. Drainage measures have been widely implemented in Ireland, under the Land Reclamation Project (1949) and then superseded by the Farm Modernisation Scheme (1974) following Ireland's entry to the European Economic Community (EEC).

It is estimated that a large proportion $(>30 \%)$ of the Boyne catchment area has been subjected to field drainage (Burdon, 1986). However, exact figures are not available due to a lack of records on implementation, because the physical work of drainage was undertaken at a local scale by individual farmers. When field and arterial drainage measures were implemented they were intended to work in tandem, with the efficiency of field works reliant on the increased capacity of receiving river channels to convey additional runoff. Due to their close association, WH 6 and WH 7 are regarded as a single driver of change (drainage) in the further analysis.

\subsubsection{Precipitation regime}

Kiely (1999) originally linked the observed change point in streamflow in the Boyne to increases in precipitation driven by the NAO. Hence, WH 8 (changes in precipitation) is also included for further analysis. The NAO is the dominant mode of natural climate variability in the region (Hurrell and Van Loon, 1997; Wilby et al., 1997), with positive phases of the NAO index associated with increased westerly airflow and positioning of storm tracks over north-western Europe. The NAO influence in winter has subsequently been linked to extreme rainfalls (Maraun et al., 2011), winter runoff (Laizé and Hannah, 2010), high flows (Hannaford and Marsh, 2008) and enhanced orographic rainfall (Burt and Howden, 2013) in the British Isles. Similarly, Leahy and Kiely (2011) report an increase in March and October hourly rainfall in 1975 across Ireland, with a corresponding decrease in July rainfall. These changes are concurrent with a shift in the winter NAO index to a more positive phase. They further note that annual totals and seasonal distributions of rainfall have changed most in the west and north-west of Ireland. Kingston et al. (2006) undertook a comprehensive review of the NAO and hydrological variables and found a positive correlation between winter NAO and streamflow for most of north-western Europe.

\section{Data and methods}

Four favoured hypotheses of change emerge from our preliminary screening of WHs in Sect. 2: drainage (WHs 6 and 7); precipitation (WH 8); or combined effects of drainage with precipitation (WH 10). To obtain a better understanding of the influence of drainage on hydrological behaviour in the Boyne, rainfall-runoff models forced with climate variables (precipitation and PET) were used to simulate a control catchment using data before the known disturbance. Therefore unlike observed flows, reconstructed streamflow time series are free from the effect of drainage. Statistical tests for both monotonic trend and change points were then employed to explore signatures of change in observed and reconstructed streamflow. The following sections describe the data and each step of the methodology.

\subsection{Hydro-climatic data}

Meteorological and streamflow data were obtained from Met Éireann (the Irish Meteorological Service) and OPW respectively. Daily data from three precipitation stations were averaged to produce catchment area precipitation (see Fig. 2, red points and Table 2). Data for Navan and Mullingar were not available post-2003, so data from Warrenstown were used to extend the catchment average to 2009. Raw data for Warrenstown slightly underestimate the 1952-2003 catchment average; hence monthly correction factors were applied to Warrenstown from 2004 to 2009 following the method of Barker et al. (2004). Here, correction factors were calculated for each month by dividing the sum of monthly total precipitation from the 1952-2003 catchment average by the sum of the total monthly precipitation from Warrenstown over the same period (Table 2). These correction factors were then 
Table 2. Stations and correction factors used to obtain catchment average precipitation.

\begin{tabular}{|c|c|c|c|c|c|c|c|c|c|c|c|c|}
\hline Station no. & \multicolumn{4}{|c|}{ Station name } & \multicolumn{4}{|c|}{ Period } & \multicolumn{4}{|c|}{ ma.s.l. } \\
\hline 2531 & \multicolumn{4}{|c|}{ Navan } & \multicolumn{4}{|c|}{$1952-2003$} & \multicolumn{4}{|c|}{52} \\
\hline 2922 & \multicolumn{4}{|c|}{ Mullingar } & \multicolumn{4}{|c|}{$1952-2003$} & \multicolumn{4}{|c|}{101} \\
\hline 2931 & \multicolumn{4}{|c|}{ Warrenstown } & \multicolumn{4}{|c|}{ 1952-2009 } & \multicolumn{4}{|c|}{90} \\
\hline $\begin{array}{l}\text { Correction } \\
\text { factor }\end{array}$ & $\begin{array}{c}\text { Jan } \\
1.038\end{array}$ & $\begin{array}{c}\text { Feb } \\
1.039\end{array}$ & $\begin{array}{l}\text { Mar } \\
1.032\end{array}$ & $\begin{array}{c}\text { Apr } \\
1.019\end{array}$ & $\begin{array}{l}\text { May } \\
1.018\end{array}$ & $\begin{array}{c}\text { Jun } \\
1.003\end{array}$ & $\begin{array}{c}\text { Jul } \\
1.062\end{array}$ & $\begin{array}{l}\text { Aug } \\
1.001\end{array}$ & $\begin{array}{l}\text { Sep } \\
1.029\end{array}$ & $\begin{array}{c}\text { Oct } \\
1.021\end{array}$ & $\begin{array}{l}\text { Nov } \\
1.031\end{array}$ & $\begin{array}{c}\text { Dec } \\
1.014\end{array}$ \\
\hline
\end{tabular}

applied to daily Warrenstown data from 2004 to 2009 and merged with the 1952-2003 catchment average to create an extended catchment precipitation series of 58 years. Daily streamflow data for the Boyne at Slane Castle (Fig. 2, red triangle) were obtained for the period 1952-2009. Slane Castle is a velocity-area gauging station automated in 1940 with a weir acting as a control. This is one of the longest, highestquality (stable rating) records in Ireland with less than $1 \%$ missing data.

\subsection{Hydrological modelling}

CRR models were employed to reconstruct daily mean flows. Using the pre-drainage period (pre-1970) to train models allows the simulation of streamflow series as if there are no impact of drainage. All CRR models are subject to uncertainties stemming from input data, parameter and model structure uncertainty. It is well known that different combinations of plausible parameter sets within a hydrological model structure can simulate the observed flow to a similar extent - the concept of equifinality (Beven and Binley, 1992). The same concept also applies to model structure, with a number of studies highlighting the utility of multi-model ensembles in simulating change in catchments (Butts et al., 2004; Wilby, 2005; Bastola et al., 2011), while Clark et al. (2008) highlight the challenges of identifying appropriate model structures.

To reconstruct streamflow, three structurally different hydrological models were chosen, each of which has been applied to the Boyne before (Murphy et al., 2006, 2011; Bastola et al., 2011, 2012; Hall and Murphy, 2011; Bastola and Murphy, 2013). These models are HYSIM (Manley, 1978), NAM (Madsen, 2000) and HyMOD (Boyle, 2001). While all three models are lumped, they differ in complexity as defined by the number of parameters requiring calibration and the way in which spatial heterogeneity of the catchment is represented. HYSIM and NAM describe catchment hydrology using a group of conceptual elements. HyMOD is a variable contributing area model, with spatial variability modelled using a probability distribution function. All three models employ a single linear reservoir to represent groundwater.

Each model was calibrated using streamflow data prior to widespread drainage and then used to simulate streamflow for the full period 1952-2009. The time periods for calibration and evaluation were 1952-1959 and 1960-1969 respectively, with one year used for model spin-up to stabilise state variables. No weights were applied to individual model structures or parameter sets. All models were forced with catchment average precipitation and PET data. Latin hypercube sampling (LHS) with a uniform distribution was used to generate 500 parameter sets for each model structure. Three objective functions were employed to identify behavioural parameter sets that can acceptably simulate observed predrainage flow: the Nash-Sutcliffe efficiency (NSE) (Nash and Sutcliffe, 1970); percent bias (PBIAS) (Gupta et al., 1999); and the mean absolute error (MAE) (Dawson and Wilby, 2001). NSE is a measure of the goodness of fit to the $1: 1$ line when the observed flow is plotted against modelled flow (Moriasi et al., 2007). The closer the NSE is to 1, the higher the accuracy of the hydrological model. PBIAS measures the average tendency of the modelled flow series to be larger or smaller than the observed flow expressed as percentage. Positive (negative) PBIAS values mean reconstructed flow over (under)estimated observed flow values. MAE provides the average magnitude of the residuals. Behavioural parameter sets were defined as those achieving NSE $\geq 0.75$, PBIAS $\leq|10|$ and MAE $<1 / 2$ multiplied by standard deviation of observed streamflow for that period. These thresholds ensure that unsatisfactory models are not classed as behavioural (Moriasi et al., 2007). Only parameter sets that were found to be behavioural for both calibration and evaluation periods were used for reconstructing flows.

\subsection{Trend and change point analysis}

\subsubsection{Hydrological and precipitation indicators}

Observed precipitation, observed streamflow and reconstructed streamflow series were analysed for evidence of monotonic trends and change points. Fifteen hydrological and 15 precipitation indicators were extracted for the period 1952-2009. These were

- annual mean flow (AMF)

- annual 90th percentile of daily mean flow (Q10)

- annual Richards-Baker hydrological flashiness index (RB) 
- monthly mean flow, January to December

- total annual precipitation (TAP)

- annual 90th percentile of daily precipitation totals (P10)

- annual coefficient of variation (CV) of daily precipitation totals (PCV)

- total monthly precipitation, January to December.

The RB index computes variations in flow relative to total flow and provides a useful characterisation of the way a catchment translates precipitation into streamflow (Baker et al., 2004). Q10 and P10 are high-flow/precipitation indicators defined as the flow/precipitation equalled or exceeded for $10 \%$ of the time (i.e. 90th percentile) during each year in the period 1952-2009. Hydrological and precipitation indicators were calculated in $\mathrm{m}^{3} \mathrm{~s}^{-1}$ and $\mathrm{mm}$ over period of time respectively, except for the RB index and PCV, which are dimensionless. PCV is the standard deviation divided by the mean daily precipitation totals for each year and tests for evidence of changing precipitation variability. To aid comparison between hydrological and climatological indicators, as well as with the results obtained by Kiely (1999), all indicators were derived for the calendar year (1 January to 31 December).

\subsubsection{Tests for change detection}

Evidence for monotonic trends was assessed using the Mann-Kendall test (MK) (Mann, 1945; Kendall, 1975), a non-parametric rank-based method that is widely applied in analyses of streamflow (e.g. Hannaford and Marsh, 2008; Villarini et al., 2011b; Murphy et al., 2013) and precipitation (e.g. Villiarini et al., 2011a; Guerreiro et al., 2014). The standardised MK statistic (MKZs) follows the standard normal distribution with a mean of zero and variance of one. A positive (negative) value of MKZs indicates an increasing (decreasing) trend. Statistical significance was evaluated with probability of type 1 error set at the $5 \%$ significance level. A two-tailed MK test was chosen; hence the null hypothesis of no trend (increasing or decreasing) is rejected when $|\mathrm{MKZs}|>1.96$.

The Pettitt (1979) statistic was used to identify a single change point and is extensively employed in both hydrological and precipitation change detection studies (e.g. Kiely, 1999; Zhang et al., 2008; Villarini et al., 2011a, b; Gao et al., 2011; Guerreiro et al., 2014). The Pettitt test is nonparametric and relative to other tests is less sensitive to outliers and skewed data (Pettitt, 1979). The null hypothesis (no step change in time series) against the alternative (an upward or downward change point in a given year) is tested at the $5 \%$ significance level.

Both change detection tests require data to be independent (i.e. free from serial correlation) as positive serial correlation increases the likelihood of type 1 errors or incorrect rejection of a true null hypothesis (Kulkarni and von Storch, 1995). All indicators were, therefore, checked for positive lag-1 serial correlation at the $5 \%$ level using the autocorrelation function $(\mathrm{ACF})$. The existence of a trend influences the correct estimate of serial correlation (Yue et al., 2002). Therefore to avoid the possibility of detecting significant serial correlation, when in fact none may exist, original time series were detrended to form a "trend-removed" residual series before the ACF was applied. The linear trend, $b$, used to detrend the original time series was estimated using the robust Theil-Sen approach (TSA; Theil, 1950; Sen, 1968). This is the median of all pairwise slopes in the time series:

$b=\operatorname{Median}\left(\frac{X_{j}-X_{i}}{j-i}\right) \forall i<j$,

where $X_{i}$ and $X_{j}$ are sequential data values of the time series in the years $i$ and $j$. The TSA is more suitable for use with hydro-climatic data compared to linear regression as it is a robust non-parametric method that is less sensitive to outliers (Helsel and Hirsch, 2002).

Pre-whitening was used to remove statistically significant lag-1 serial correlation from time series. The conventional pre-whitening approach (Kulkarni and von Storch, 1995) was however found to artificially remove part of the magnitude of the trend; hence a modified trend-free pre-whitening (TFPW) technique was applied (Yue at al., 2002). This has been implemented before to deal with serially correlated data when using the Mann-Kendall (e.g. Yue et al., 2002; Petrow and Merz, 2009) and Pettitt test (e.g. Busuioc and von Storch, 1996; Zhang et al., 2008). Steps involved with the TFPW procedure are described in detail by Yue et al. (2002). In summary, the trend is first removed; the lag-1 positive serial correlation is then removed; and finally the trend is added back to the time series, producing a blended TFPW time series including the original trend but without serial correlation. In this study, trend tests were only applied to the TFPW time series when significant serial correlation existed; otherwise they were applied to the original time series.

Hydro-climatic data often violate the assumptions required for statistical testing (Cohn and Lins, 2005; Clarke, 2010). To this end, Busuioc and von Storch (1996) recommend that statistical tests not be viewed as strict confirmatory tools when dealing with environmental data. Here, overreliance on statistical significance is reduced by presenting the actual MKZs statistic values and the Pettitt test $p$ values to help interpret relative differences between signatures of change in observed and reconstructed indicators, rather than relying entirely on statistical significance relative to arbitrary $p$ value thresholds. 

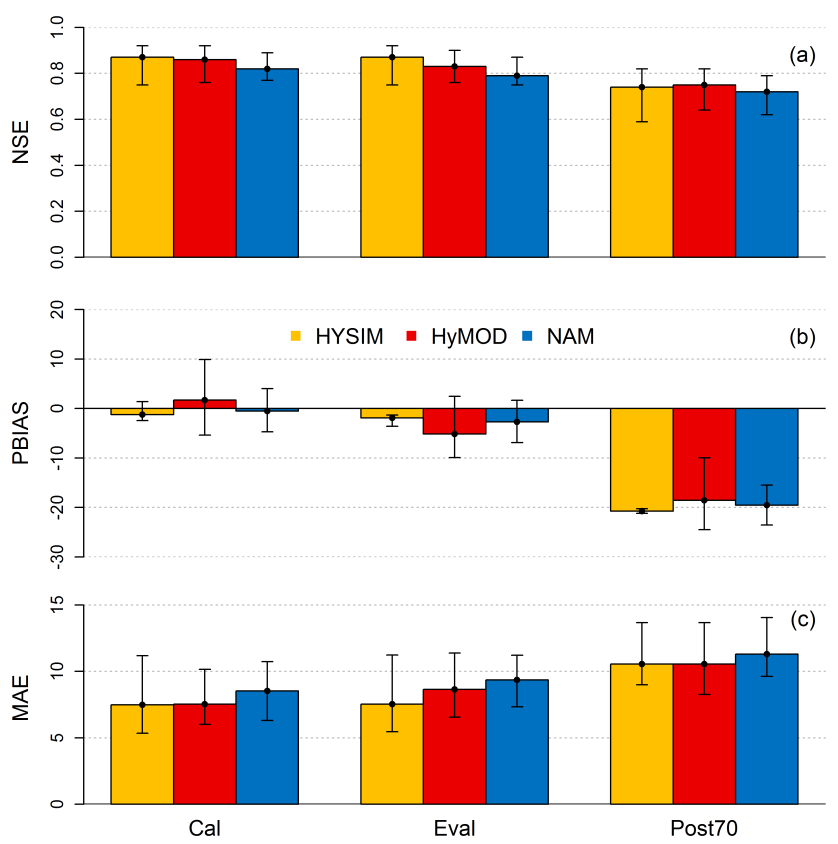

Figure 4. Objective functions (a) NSE, (b) PBIAS and (c) MAE for HYSIM, HyMOD and NAM for calibration (Cal: 1952-1959), evaluation (Eval: 1960-1969) and post-1970 (Post70: 1970-2009) periods. Each bar represents the median score for behavioural simulations, with error bars giving the maximum and minimum range.

\section{Results}

\subsection{Hydrological modelling}

Model calibration and evaluation yielded 328 out of 1500 model simulations deemed to be behavioural (HYSIM 151, HyMOD 113 and NAM 64). Figure 4 compares the performance of the three models in simulating daily mean flows during calibration (1952-1959), evaluation (1960-1969) and for the period with known disturbance, post-1970 (1970-2009). During calibration, median NSE values for each model range between 0.82 (NAM) and 0.87 (HYSIM), with the maximum NSE value of 0.92 returned for both HYSIM and HyMOD. Similarly high objective function scores are returned for the evaluation period. However, there is a large reduction in the performance of each model for the post-1970 simulation period, resulting in median NSE scores of all reconstructed flows ranging from 0.72 (NAM) to 0.74 (HYSIM). There are also large differences apparent between the reconstructed and observed PBIAS in the post-1970 period, with differences of the order of $20 \%$. Similarly, MAE values show a large increase post-1970 compared with model training periods. There is a strong degree of consistency between the three models used in all simulation periods despite the differences in model structure and complexity. Overall, during the post-1970 period, all reconstructed flows show a large discrepancy compared with observed flows. This is evident in lower NSE
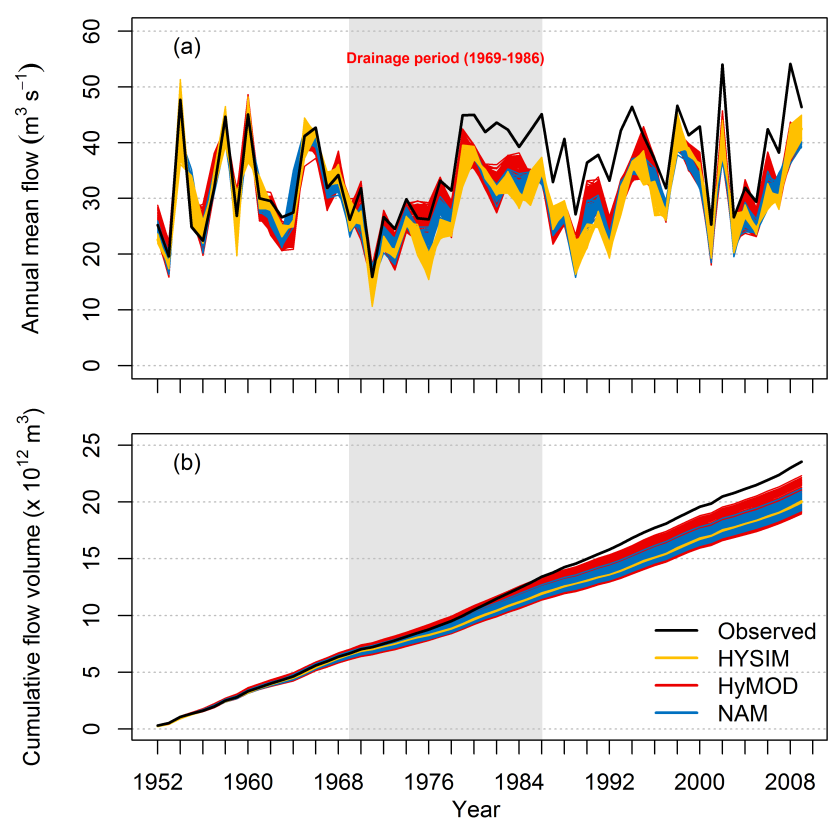

Figure 5. Annual (a) mean and (b) cumulative volume of reconstructed and observed flow for 1952-2009. The period of drainage works is shown by the shaded grey area. Behavioural simulations for each model structure are colour-coded.

values, increased PBIAS and higher MAE. Differences in model performance evidenced by PBIAS and MAE suggest that the discrepancy between reconstructed and observed flows for the post-drainage period is volumetric in nature.

Figure 5 compares time series of observed and reconstructed annual flows. Figure 5a shows close agreement between observed and reconstructed flows for both the calibration and evaluation periods, with annual mean observed flows well bounded by simulations. After 1970, reconstructed and observed mean flows start to diverge. Largest divergence occurs from the late 1970s onwards, after which none of the simulations capture the observations. Despite the large deviation, the pattern of inter-annual variability between the observed and reconstructed flows remains similar, again emphasising the volumetric nature of the discrepancy. This deviation is also apparent from the cumulative flow volume plot (Fig. 5b) where a point of inflection in the late 1970s becomes noticeable, after which a large deviation in the volume of flows occurs. The cumulative volume of flows for the full observed series is $17.6 \%$ higher than the median of the reconstructed time series. For all simulations the cumulative volume underestimation ranges from 5.5 to $24.2 \%$ for the reconstructed flow.

Figures 6 and 7 display time series of monthly mean flow and cumulative flow volume for the summer (dry) halfyear (April-September) and winter (wet) half-year (OctoberMarch) respectively. Greatest divergence between observed and reconstructed flows is apparent for months within the winter half-year. Conversely, within the summer half-year 

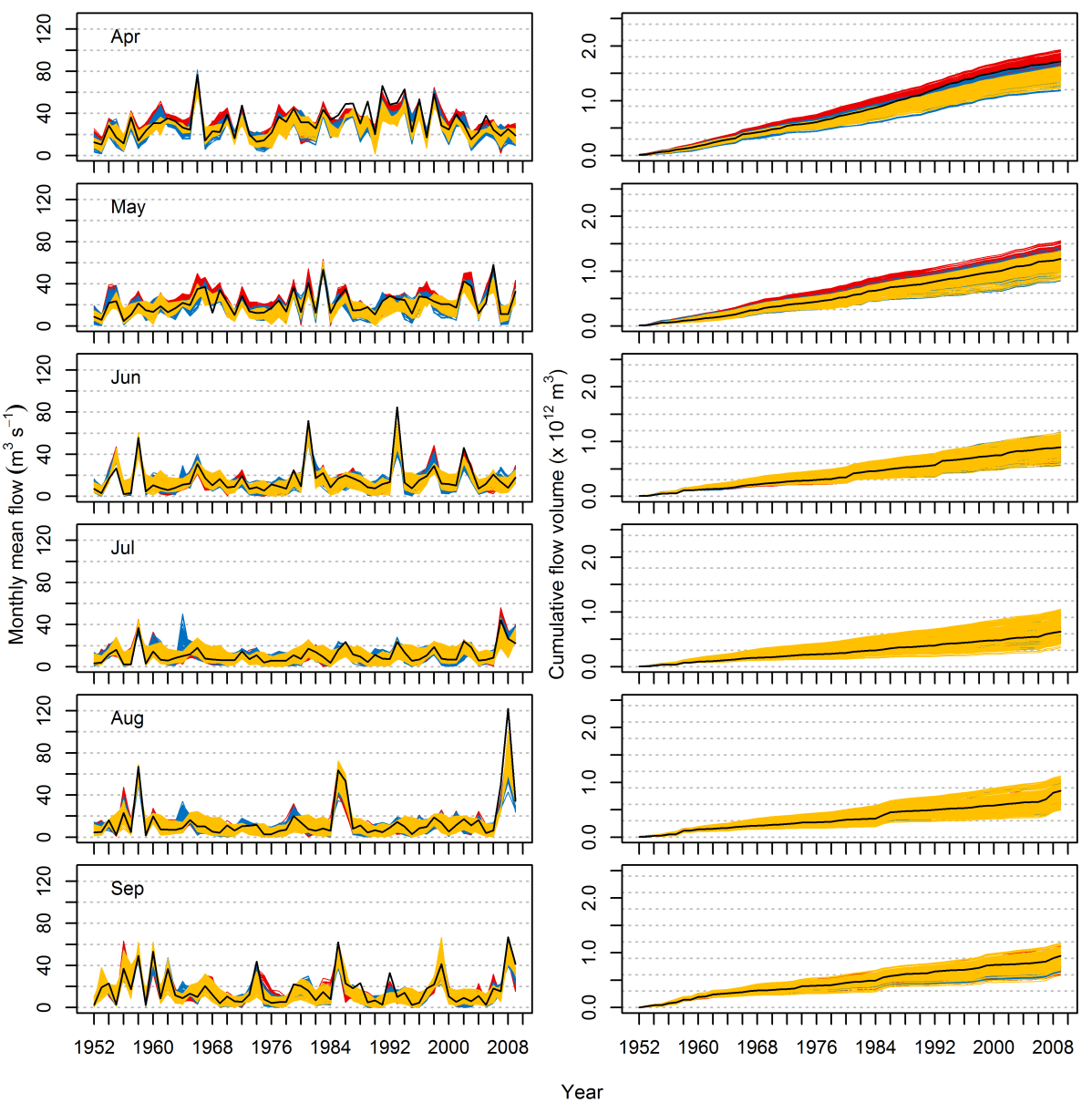

Figure 6. Monthly (left panels) mean and (right panels) cumulative volume of reconstructed and observed flow for 1952-2009 for the summer half-year (April to September). Colour code as in Fig. 5.

only April shows any substantial evidence of divergence. Observed series lie near the centre of the reconstructed flows for other summer months.

Reconstructions for months within the winter half-year again show good agreement with observed monthly mean flow for the calibration and evaluation periods (Fig. 7, left panels). However, for the post-drainage period a large divergence is evident, particularly from the cumulative flow volume plots (Fig. 7, right panels) where the observed series lies at the very upper bounds or outside reconstructed flows in the majority of months (particularly during December, January and February). The magnitude of divergence in winter half-year months highlights their dominant contribution to the divergence evident in the annual observed flow.

\subsection{Trend and change point analysis}

In total 15 observed precipitation, 15 observed streamflow and 4920 reconstructed streamflow series (i.e. 15 indicators by 328 reconstructed series) were generated for further analysis for the period 1952-2009. Use of the term "significant" below refers to changes at $p=0.05$ level.

\subsubsection{Serial correlation}

When analysing observed indicators for serial correlation only March and August mean flows show significant positive lag-1 serial correlation. This is also reflected in the reconstructed flow series with 81 and $79 \%$ of reconstructed simulations for March and August mean flow exhibiting serial correlation respectively. Four other reconstructed indicators have a smaller degree of significant serial correlation: AMF (33\% of the reconstructed series) and, to a lesser extent, the RB index (3\%), September (5\%) and June (2\%) mean flow reconstructions. No precipitation indicators were significantly serially correlated. For observed streamflow indicators with significant serial correlation MK and Pettitt tests were applied to both original and TFPW time series for comparison. 

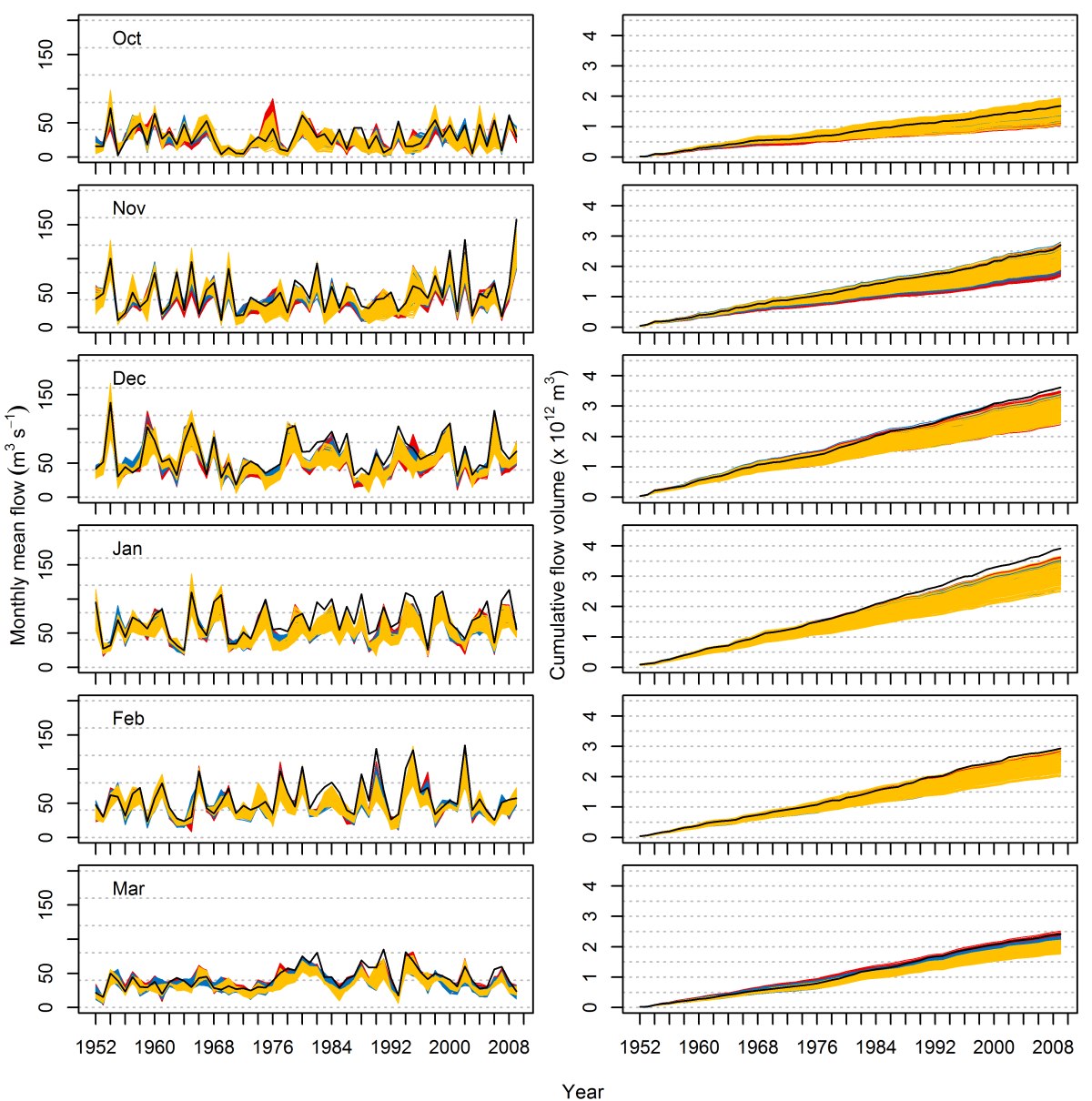

Figure 7. As in Fig. 6 but for the winter half-year (October to March).

\subsubsection{Monotonic trend}

Results from the monotonic trend analysis for the period 1952-2009 using the MK test are presented in Fig. 8. Observed indicators consistently show larger MKZs values than reconstructed. Observed AMF shows a significant increasing monotonic trend with the strongest positive MKZs value (3.1) in the analysis. None of the reconstructed AMF time series or observed TAP show significant trends. Similarly, observed Q10 shows a significant increasing trend (MKZs 2.6), while P10 shows a non-significant increasing trend (MKZs 0.85). The median MKZs for reconstructed Q10 is 1.14, with one reconstructed Q10 series showing a barely significant trend (MKZs 1.97). A near significant increasing trend is found for the observed RB index (MKZs 1.93) with none of the reconstructed data or PCV (MKZs 1.58) exhibiting a significant trend.

All observed monthly mean flow indicators show increasing monotonic trends over the period 1952-2009 with significant trends for January, March, June and July. When serial correlation is accounted for, the strength of trends in March and August reduces. For the reconstructed monthly flow

indicators the majority of the series reveal non-significant increasing trends with the exception of September and October, which show non-significant decreasing trends. Only in May is there evidence of several significant trends in reconstructed series, with $16 \%$ showing significant increasing trends. For reconstructed June mean flows, one model from 328 behavioural simulations shows a significant increasing trend. Observed precipitation did not reveal significant trends in any of the 15 indicators, with the relative strength of trends being much weaker than observed flow for corresponding metrics.

\subsubsection{Change point}

Results from the Pettitt change point test are presented in Fig. 9 for selected indicators. For all identified change points the time series increase after the stated change point year. A significant change point is found in $1978(p<0.001)$ in observed AMF. Observed TAP and $85 \%$ of reconstructed AMF series reveal non-significant change points also in 1978. For the remaining $15 \%$ of reconstructed AMF series non-significant change points are shown for 1993. Observed 


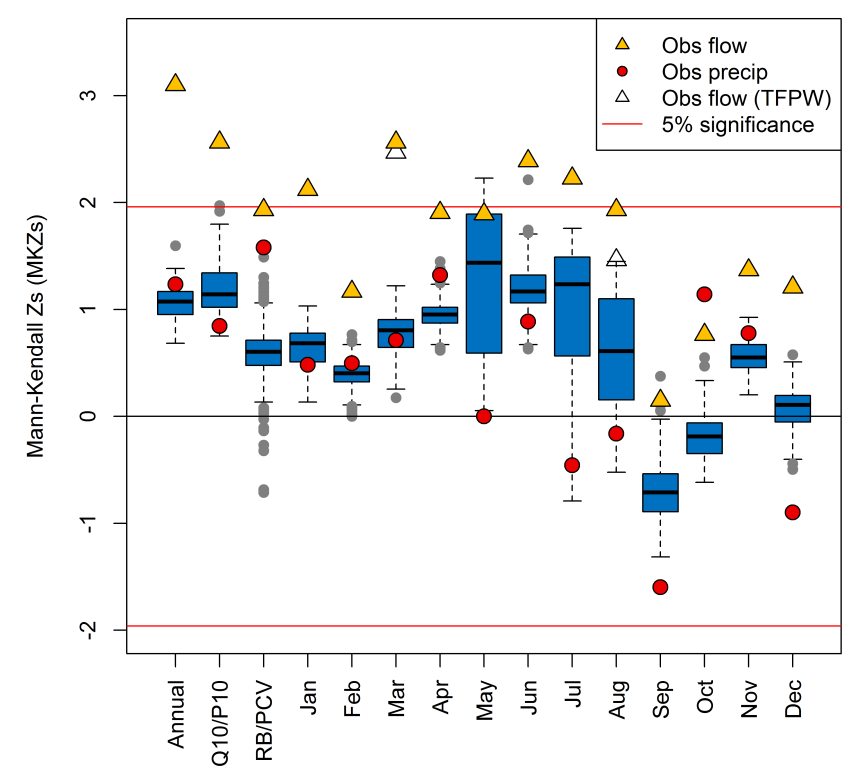

Figure 8. Mann-Kendall tests for monotonic trend in precipitation and flow indicators. MKZs values above (below) $5 \%$ significance line $(|\mathrm{MKZs}|>1.96)$ indicate significant increasing (decreasing) trends. Boxplots summarise MKZs values for 328 reconstructed time series, with the black line representing the median, and boxes the interquartile range (IQR); whiskers extend to the most extreme data point, which is no more than 1.5 times the IQR from the box, and grey circles are outliers beyond this range.

annual Q10 also shows a significant upward change point in $1978(p=0.004)$, with $61 \%$ of models showing a nonsignificant change point for the same year; the remaining simulations show non-significant change points in different years. For P10 there is a non-significant $(p=0.12)$ change point in 1977. A significant change point in $1982(p=0.014)$ is found for the observed RB index with no significant changes in the reconstructed RB series for that year and several non-significant change points in other parts of the reconstructed series. In addition, there is a non-significant change in PCV in $2002(p=0.098)$.

For monthly indicators observed January mean flow shows a non-significant $(p=0.086)$ change point in 1978 . A total of $31 \%$ of reconstructed January flows also show nonsignificant change points for the same year. However, there is a large difference in the strength of changes, with reconstructed series having median $p=0.558$. January precipitation shows a non-significant change point in $1964(p=0.7)$. In March, a significant change point is detected in both observed mean flow (TFPW series, $p=0.0012$ ) and total precipitation $(p=0.044)$ in 1975 , with $7 \%$ of reconstructed time series having a change point in 1976. The March total is the only precipitation indicator with a significant change point.

Serial correlation has a large influence on results for March mean flows. Before serial correlation was accounted for, the change point in observations occurred one year later in $1976(p<0.001)$, while $85 \%$ of reconstructed series showed a significant change point between 1975 and 1977. Despite the large reduction in the number of reconstructed series showing a significant change point after application of TFPW, the relative difference between observed and reconstructed $p$ values around the mid-1970s is the closest of all the indicators shown in Fig. 9. Other statistically significant change points (not shown) occurred in observed monthly mean flow in April (1976), June (1978) and July (1978). For reconstructed April and June mean flows less than $3 \%$ of simulations show significant changes in the same year, with none reproducing a significant change in 1978 for July.

\section{Discussion}

\subsection{Attribution of change in Boyne streamflow}

Following a preliminary assessment of multiple potential drivers of hydrological change, the contribution of climate (WH 8 precipitation) and internal factors (WH 6 and 7 drainage) to the detected mid-1970s change point in Boyne streamflow were explored. Reconstructed flows obtained from behavioural simulations from three structurally different CRR models do not show the trend and change point found in observed AMF in 1978 when only climate variability is considered. While this discrepancy is particularly evident for high flows (Q10) and during winter months (Fig. 7, right panels), there is some evidence of statistically significant changes in observed June and July mean streamflow. However, a statistically significant change in summer (i.e. low flows) contributes little to the large detected change point in observed AMF (see Fig. 6, right panels). Additionally, there is no evidence of a trend or change point in TAP, $\mathrm{P} 10$ or precipitation totals in winter months. While it is important to test for both gradual and abrupt changes, given that different drivers have effects at different time scales, it is clear from visual inspection of time series (Figs. 1, 5 and 10) that the observed change in Boyne streamflow is abrupt and therefore detected trends are an artefact of change points rather than real gradual linear changes. This further supports the assumption that drivers with longer-term gradual or linear effects are less important in this context.

Given that reconstructed flows contain precipitation as a key forcing variable, it is therefore unlikely that changes in flow observations are driven entirely by a change in precipitation (WH 8). The observed RB index was found to increase post-1982, while the PCV (coefficient of variation of daily precipitation) did not change significantly. Changes in RB index have been previously linked to human disturbance within catchments (e.g. Baker et al., 2004; Holko et al., 2011). An increase in flashiness is consistent with the effects of drainage, where there is an acceleration of the response to rainfall with flood peaks of increased intensity (Lynn, 1981). 


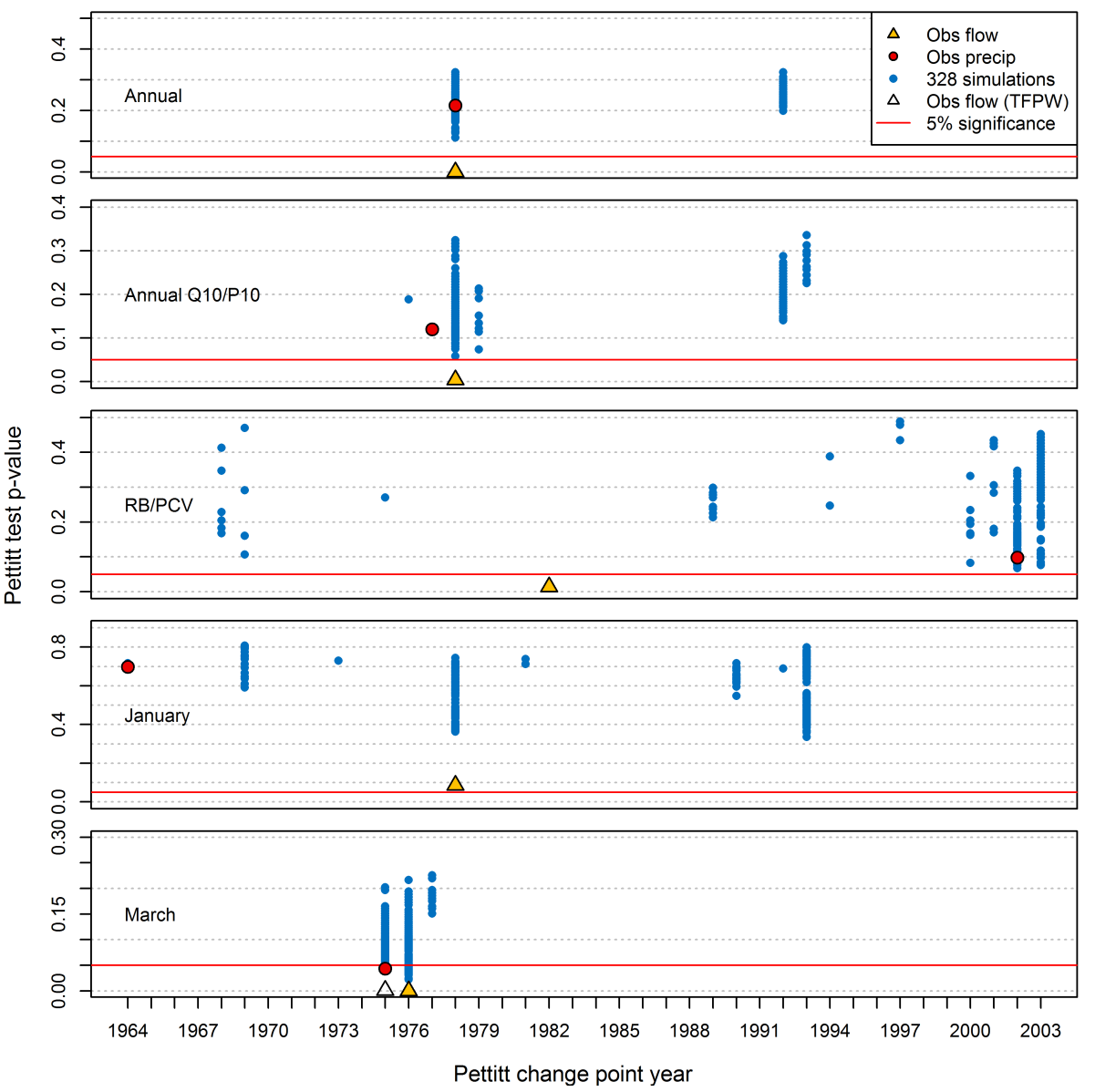

Figure 9. Pettitt test for change points in selected indicators. Solid red lines represent the threshold for significant change points at the $5 \%$ level, with $p$ values below (above) indicating a significant (non-significant) change point for corresponding year of change on the $x$ axis.

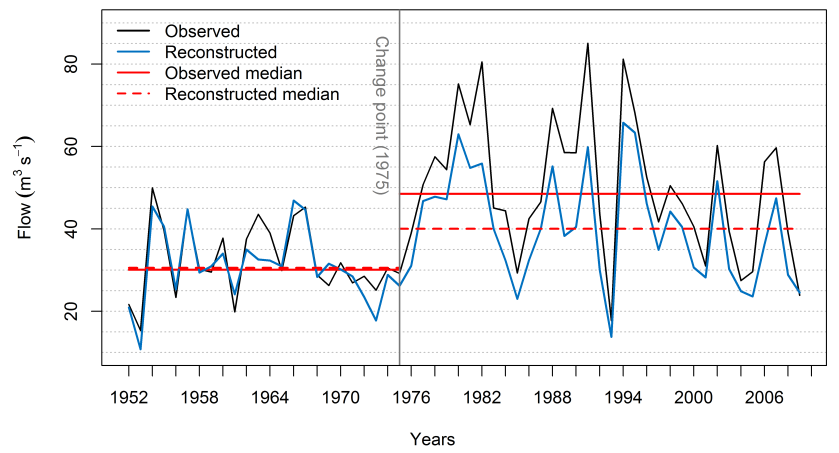

Figure 10. Observed and median of 328 reconstructed series for March mean flow. Solid red line is the observed median flow before (1952-1975) and after (1976-2009) the detected change point; dash red is the reconstructed median flow for the same periods.

However, the influence of precipitation change cannot be completely discounted. A significant (5\% level) change point in 1975 was detected in March for both observed mean flow and precipitation totals, with reconstructed series showing evidence of a change around the same time. This is further supported by visual inspection of the time series for observed and reconstructed March mean flows in Fig. 10. The plot shows the median of observed and reconstructed time series before and after 1975. Evident is the close agreement between series before the change point, while an increase in the median of March mean flows is apparent after 1975 in both observed and reconstructed flows. Of note, however, is the larger change in observations which can be interpreted as a combined influence, of similar magnitude, from drainage and precipitation. This is consistent with the hypothesis of increased March precipitation after 1975 being magnified by an altered rainfall-runoff response of the catchment following drainage, which also increases flashiness.

In light of these findings, it is unlikely that observed changes in the flow regime of the Boyne are driven solely by changes in precipitation as a result of a shift in the NAO index from a negative to positive phase in the mid-1970s. While detection of the change point in annual and March observed mean flow by Kiely (1999) is confirmed here, attribution of change is different. We assert that the dominant driver of change in observed AMF and Q10 is arterial and field drainage (WH 6 and 7). Data on the extent and timing 
of arterial drainage show that the majority of dredging in major channels was completed between the late 1970s and early 1980s, thereby facilitating widespread field drainage. Differences in response between observed and reconstructed flows are consistent with current understanding of the impact of drainage, with largest divergence evident in wetter months. Results for March suggest that there is an influence from both internal and climatic drivers of change, by which drainage magnifies the signal of the mid-1970s abrupt change in precipitation. Therefore, in line with WH 10 (multiple drivers/synergetic effects) we postulate that the attribution of abrupt change evident in observations is driven predominantly by drainage at the annual and high-flow scale and in March by comparable contributions of both drainage and precipitation change. Future work should examine whether change in March precipitation is most strongly linked to a change in the NAO or other regional-scale atmospheric circulation.

\subsection{Confidence in attribution}

To qualify our explanation for hydrological change in the Boyne a critical examination of uncertainties and assumptions in the methodology is required (after Merz et al., 2012). While our approach accommodates uncertainties from rainfall-runoff model structure and parameters, it is assumed that the simulations reflect the full hydrological response of the catchment. Model inter-comparison tests (e.g. Reed et al., 2004; Duan et al., 2006) indicate a wide range of simulations when many different model structures are forced with the same input. In this study only when all three models are combined is the full range of observed flows in the pre-drainage series (calibration and evaluation period) captured. This highlights the importance of considering multiple model structures and signals potential benefits from applying generic model structures such as the Framework for Understanding Structural Errors (FUSE; Clark et al., 2008) in detection and attribution studies.

Positive serial correlation has a large influence on the statistical significance of results. There are several ways of dealing with this. We applied pre-whitening (TFPW) before application of statistical tests, but block bootstrapping has also been used (e.g. Önöz and Bayazit, 2012; Murphy et al., 2013). The large reduction in the number of statistically significant change points in reconstructed March mean flows reported above also occurred when block bootstrapping was applied (not shown). The influence of serial correlation on statistical change detection is particularly important when using reconstructed time series given the high degree of serial correlation that can be introduced by soil moisture accounting algorithms or "memory" of CRR models (Evin et al., 2013). However, of greater importance in this approach is the relative difference in the statistics derived from observed and reconstructed series, rather than significance based on arbitrary $p$ value thresholds.
There is unavoidable subjectivity in identification of potential working hypotheses and exclusion of some WHs from detailed assessment (Table 1). Substantial effort was made to include all plausible drivers of change. MMWH also accepts that other currently unknown factors (WH 11) may emerge as important drivers of change given further research, recognising attribution as an iterative process. Furthermore not all drivers can be quantitatively analysed and excluded on that basis. Here, treated water discharges (WH 3), urbanisation (WH 4) and forest cover and management change (WH 5) were considered second-order influences based on available data and the nature of change in streamflow observations. Although the scale of land-use change, such as urban and forest cover, is modest and unlikely to be influential in a catchment of this size (Blöschl et al., 2007), there is little data to quantify such impacts in the Boyne. There is also no control case for large catchments compared to small experimental watersheds, where a paired catchment approach can be used to examine impacts of land-use changes (Hewlett, 1982; Brown et al., 2005).

\subsection{Towards more rigorous attribution}

A detected change in streamflow is the integrated response to all drivers, climate and internal, natural and human-induced. This makes attribution of hydrological change inherently challenging. However, we have demonstrated that valuable insights can emerge from application of MMWH which enables systematic consideration of multiple drivers, helping to postulate new hypotheses and importantly highlighting weaknesses in current understanding, while still acknowledging the possibility of unknown drivers. Ideally, an attribution study will establish whether change is driven by climate and/or internal disturbances, as management responses to the detected driver could be very different. Here, this was achieved with the aid of hydrological simulation. It was also shown that human disturbance can have larger impacts on the hydrological system than climate at the catchment scale.

Even for the Boyne, where relatively rich data sources are available in comparison to other catchments, full confidence in attribution cannot be achieved. Our conclusions are founded on an assessment of inconsistency, while hard attribution also requires evidence of consistency (Merz et al., 2012). Data were gathered for precipitation, PET, streamflow, the NAO, land-use and soil types and supplemented with documentary evidence from hydrometric and drainage archives. In pursuing evidence of consistency physically based models could be used to explicitly represent arterial and field drainage systems. However, the value added by more complex modelling of artificial drainage at the scale of the Boyne is contingent on the availability of detailed data on the timing and location of local channel changes. Hard attribution is fundamentally problematic for historic changes where data can be more qualitative in nature. Hence rigorous 
attribution will require investment in monitoring change in catchments, beyond typical hydrological variables.

We agree with Merz et al. (2012) that advancement in attribution is an iterative process whereby revealing weaknesses in established hypotheses of change can lead to improved overall understanding of dominant drivers of change. In this study coupled interactions and feedbacks between human and natural components of the catchment system are apparent. For example, the economic imperative for increased agricultural productivity was the main motivation for implementing drainage, facilitated through structural funds available by the accession of Ireland to the EEC. In the face of such complexity MMWH offers a formal structure within which to build and refine hypotheses of change.

\section{Conclusions}

Attributing changes in streamflow to climate drivers cannot take place without reference to other human-induced catchment disturbances. This paper revisited an attributed change point in observed streamflow in the Boyne (Kiely, 1999) using MMWH and the Merz et al. (2012) attribution framework. Evidence of consistency and inconsistency with the detected change was systematically examined given a set of credible external and internal drivers. Changes in precipitation and a combination of arterial and field drainage, as well as possible synergistic effects, were brought forward for further analysis. CRR models were employed to reconstruct streamflow in the absence of drainage, while statistical tests were used to detect monotonic trends and change points in reconstructed and observed flows.

We find that climate variability is not the only possible driver of hydrological change in the Boyne. Arterial drainage and the simultaneous onset of field drainage in the 1970s and early 1980s were inferred to be the predominant driver of change in observed annual mean and high flows. Wetter, winter months contribute most to the large 1978 change point found in annual and high flows. However, a change in precipitation regime is also reflected in March mean flow, with observed and reconstructed runoff showing a contemporaneous upward change point in 1975, although the observed change is amplified by the effect of drainage. Our new explanation posits that multiple drivers acting simultaneously were responsible for observed changes in Boyne streamflow, but detectable in different aspects of the flow regime.

This study shows the range of data types needed for rigorous attribution, especially where substantial human modifications to catchments may be involved. The method of multiple working hypotheses compels the researcher to review all plausible drivers of change, thus avoiding confirmation bias, in addition to identifying key weakness in current understanding of change within a catchment. A key weakness here was the limited information and data availability on the impact of urbanisation and forest cover change on hydrological behaviour. These knowledge gaps create opportunities for future research. Attribution of hydrological change is a challenging task, but understanding the interplay and co-evolution of human and natural hydrological dynamics (Sivapalan et al., 2012) is essential to the discipline (Montanari et al., 2013). It is of great societal importance that signals of human disturbance and natural and anthropogenic climate change within the hydrological system are detected and properly attributed so that effective management responses are invoked.

Acknowledgements. This research was funded by Science Foundation Ireland (SFI) and the Irish Research Council (IRC). Julia Hall acknowledges support by the ERC Advanced Grant "Flood Change", project no. 615 291152. Statistical analyses and graphics were implemented in the open-source R statistical computing software. We thank personnel in the OPW hydrometrics and drainage divisions for their expertise and access to archival records. We also thank Satish Bastola for automating the use of NAM and HyMOD, Colin Holman for automating HYSIM, and Gerald Mills (UCD) and Réamonn Fealy (Teagasc) for providing feedback on an earlier version of this manuscript. Finally we thank Sergiy Vorogushyn and an anonymous referee for their valuable review comments.

Edited by: G. Di Baldassarre

\section{References}

Andréassian, V., Parent, E., and Michel, C.: A distribution-free test to detect gradual changes in watershed behavior, Water Resour. Res., 39, 1252, doi:10.1029/2003WR002081, 2003.

Bailey, A. D. and Bree, T.: Effect of improved land drainage on river flow, in: Flood Studies Report - five Years on, Thomas Telford, London, 131-142, 1981.

Baker, D. B., Richards, R. P., Loftus, T. T., and Kramer, J. W.: A New Flashiness Index: Characteristics and Applications to Midwestern Rivers and Streams, J. Am. Water Resour. As., 40, 503522, doi:10.1111/j.1752-1688.2004.tb01046.x, 2004.

Barker, P. A., Wilby, R. L., and Borrows, J.: A 200-year precipitation index for the central English Lake District, Hydrolog. Sci. J., 49, 769-785, 2004.

Bastola, S. and Murphy, C.: Sensitivity of the performance of a conceptual rainfall-runoff model to the temporal sampling of calibration data, Hydrol. Res., 44, 484-494, 2013.

Bastola, S., Murphy, C., and Sweeney, J.: The role of hydrological modelling uncertainties in climate change impact assessments of Irish river catchments, Adv. Water Resour., 34, 562-576, 2011.

Bastola, S., Murphy, C., and Fealy, R.: Generating probabilistic estimates of hydrological response for Irish catchments using a weather generator and probabilistic climate change scenarios, Hydrol. Process., 26, 2307-2321, doi:10.1002/hyp.8349, 2012.

Beven, K. and Binley, A.: The future of distributed models: Model calibration and uncertainty prediction, Hydrol. Process., 6, 279298, doi:10.1002/hyp.3360060305, 1992. 
Bhattarai, K. P. and O'Connor, K. M.: The effects over time of an arterial drainage scheme on the rainfall-runoff transformation in the Brosna Catchment, Phy. Chem. Earth, 29, 787-794, 2004.

Blöschl, G., Ardoin-Bardin, S., Bonell, M., Dorninger, M., Goodrich, D., Gutknecht, D., Matamoros, D., Merz, B., Shand, P., and Szolgay, J.: At what scales do climate variability and land cover change impact on flooding and low flows?, Hydrol. Process., 21, 1241-1247, doi:10.1002/hyp.6669, 2007.

Boyle, D. P.: Multicriteria calibration of hydrological models, Ph.D. Thesis, University of Arizona, USA, 2001.

Bradford, R. B. and Marsh, T. J.: Defining a network of benchmark catchments for the UK, Proc. Inst. Civil Eng., 156, 109-116, doi:10.1680/wame.2003.156.2.109, 2003.

Bree, T. and Cunnane, C.: Evaluating the effects of arterial drainage on river flood discharges, Annexe 1, Office of the Public Works, Dublin, Ireland, 1979.

Brown, A. E., Zhang, L., McMahon, T. A., Western, A. W., and Vertessy, R. A.: A review of paired catchment studies for determining changes in water yield resulting from alterations in vegetation, J. Hydrol., 310, 28-61, 2005.

Burdon, D. J.: Hydrogeological Aspects of Agricultural Drainage in Ireland, Environ. Geol. Water S., 9, 41-65, 1986.

Burn, D. H., Sharif, M., and Zhang, K.: Detection of trends in hydrological extremes for Canadian watersheds, Hydrol. Process., 24, 1781-1790, doi:10.1002/hyp.7625, 2010.

Burt, T. P. and Howden, N. J. K.: North Atlantic Oscillation amplifies orographic precipitation and river flow in upland Britain, Water Resour. Res., 49, 3504-3515, doi:10.1002/wrcr.20297, 2013.

Busuioc, A. and von Storch, H.: Changes in the winter precipitation in Romania and its relation to the large-scale circulation, Tellus A, 48, 538-552, 1996.

Butts, M. B., Payne, J. T., Kristensen, M., and Madsen, H.: An evaluation of the impact of model structure on hydrological modelling uncertainty for streamflow simulation, J. Hydrol., 298, 242-266, 2004.

Chamberlin, T. C.: The Method of Multiple Working Hypotheses, Science, 15, 92-96, 1890.

Clark, M. P., Slater, A. G., Rupp, D. E., Woods, R. A., Vrugt, J. A., Gupta, H. V., Wagener, T., and Hay, L. E.: Framework for Understanding Structural Errors (FUSE): A modular framework to diagnose differences between hydrological models, Water Resour. Res., 44, W00B02, doi:10.1029/2007WR006735, 2008.

Clark, M. P., Kavetski, D., and Fenicia, F.: Pursuing the method of multiple working hypotheses for hydrological modeling, Water Resour. Res., 47, W09301, doi:10.1029/2010WR009827, 2011.

Clarke, R. T.: On the (mis) use of statistical methods in hydroclimatological research, Hydrolog. Sci. J., 55, 139-144, 2010.

Cohn, T. A. and Lins, H. F.: Nature's style: Naturally trendy, Geophys. Res. Lett., 32, L23402, doi:10.1029/2005GL024476, 2005.

Dawson, C. W. and Wilby, R. L.: Hydrological modelling using artificial neural networks, Prog. Phys. Geogr., 25, 80-108, 2001.

Duan, Q., Schaake, J., Andréassian, V., Franks, S., Goteti, G., Gupta, H. V., Gusev, Y. M., Habets, F., Hall, A., Hay, L., Hogue, T., Huang, M., Leavesley, G., Liang, X., Nasonova, O. N., Noilhan, J., Oudin, L., Sorooshian, S., Wagener, T., and Wood, E. F.: Model Parameter Estimation Experiment (MOPEX): An overview of science strategy and major results from the second and third workshops, J. Hydrol., 320, 3-17, doi:10.1016/j.jhydrol.2005.07.031, 2006.
Durack, P. J., Wijffels, S. E., and Matear, R. J.: Ocean Salinities Reveal Strong Global Water Cycle Intensification During 1950 to 2000 , Science, 336, 455-458, doi:10.1126/science.1212222, 2012.

Elliott, L. P. and Brook, B. W.: Revisiting Chamberlin: Multiple Working Hypotheses for the 21st Century, BioScience, 57, 608614, doi:10.1641/B570708, 2007.

EPA: The Provision and Quality of Drinking Water in Ireland A Report for the Years 2007-2008, Environmental Protection Agency (EPA), Johnstown Castle, Wexford, Ireland, 2009.

EPA: Integrated Pollution Prevention and Control (IPCC) Licence no. P0516-03 for Boliden Tara Mines Limited, Environmental Protection Agency (EPA), Johnstown Castle, Wexford, Ireland, 2012.

Evin, G., Kavetski, D., Thyer, M., and Kuczera, G.: Pitfalls and improvements in the joint inference of heteroscedasticity and autocorrelation in hydrological model calibration, Water Resour. Res., 49, 4518-4524, doi:10.1002/wrcr.20284, 2013.

Fenicia, F., Savenije, H. H. G., and Avdeeva, Y.: Anomaly in the rainfall-runoff behaviour of the Meuse catchment. Climate, landuse, or land-use management?, Hydrol. Earth Syst. Sci., 13, 1727-1737, doi:10.5194/hess-13-1727-2009, 2009.

Frans, C., Istanbulluoglu, E., Mishra, V., Munoz-Arriola, F., and Lettenmaier, D. P.: Are climatic or land cover changes the dominant cause of runoff trends in the Upper Mississippi River Basin?, Geophys. Res. Lett., 40, 1104-1110, doi:10.1002/grl.50262, 2013.

Gao, P., Mu, X.-M., Wang, F., and Li, R.: Changes in streamflow and sediment discharge and the response to human activities in the middle reaches of the Yellow River, Hydrol. Earth Syst. Sci., 15, 1-10, doi:10.5194/hess-15-1-2011, 2011.

Gebrehiwot, S. G., Seibert, J., Gärdenäs, A. I., Mellander, P.-E., and Bishop, K.: Hydrological change detection using modeling: Half a century of runoff from four rivers in the Blue Nile Basin, Water Resour. Res., 49, 3842-3851, doi:10.1002/wrcr.20319, 2013.

Guerreiro, S. B., Kilsby, C. G., and Serinaldi, F.: Analysis of time variation of rainfall in transnational basins in Iberia: abrupt changes or trends?, Int. J. Climatol., 34, 114-133, doi:10.1002/joc.3669, 2014.

Gupta, H. V., Sorooshian, S., and Yapo, P. O.: Status of automatic calibration for hydrologic models: Comparison with multilevel expert calibration, J. Hydrol. Eng., 4, 135-143, 1999.

Hall, J. and Murphy, C.: Robust adaptation assessment - climate change and water supply, Int. J. Clim. Change Strat. Manage., 3, 302-319, 2011.

Hannaford, J. and Buys, G.: Trends in seasonal river flow regimes in the UK, J. Hydrol., 475, 158-174, 2012.

Hannaford, J. and Marsh, T. J.: High-flow and flood trends in a network of undisturbed catchments in the UK, Int. J. Climatol., 28, 1325-1338, doi:10.1002/joc.1643, 2008.

Helsel, D. R. and Hirsch, R. M.: Statistical methods in water resources, Techniques of water-resources investigations, Book 4, chapter A3, http://pubs.usgs.gov/twri/twri4a3/, last access: 23 September 2013, US Geological Survey, 522 pp., 2002.

Hewlett, J. D.: Principles of Forest Hydrology, University of Georgia Press, Athens, 1982.

Holko, L., Parajka, J., Kostka, Z., Škoda, P., and Blöschl, G.: Flashiness of mountain streams in Slovakia and Austria, J. Hydrol., 405, 392-401, 2011. 
Hundecha, Y. and Merz, B.: Exploring the relationship between changes in climate and floods using a model-based analysis, Water Resour. Res., 48, W04512, doi:10.1029/2011WR010527, 2012.

Huntington, T. G.: Evidence for intensification of the global water cycle: Review and synthesis, J. Hydrol., 319, 83-95, doi:10.1016/j.jhydrol.2005.07.003, 2006.

Hurrell, J. W. and Van Loon, H.: Decadal variations in climate associated with the North Atlantic Oscillation, Climatic Change, 36, 301-326, 1997.

Institute of Hydrology: Flood Estimation Handbook (five volumes), Centre for Ecology \& Hydrology, Wallingford, UK, 1999.

Jia, Y., Ding, X., Wang, H., Zhou, Z., Qiu, Y., and Niu, C.: Attribution of water resources evolution in the highly water-stressed Hai River Basin of China, Water Resour. Res., 48, W02513, doi:10.1029/2010WR009275, 2012.

Kendall, M. G.: Rank correlation methods, Charles Griffin, London, 1975.

Kiely, G.: Climate change in Ireland from precipitation and streamflow observations, Adv. Water Resour., 23, 141-151, 1999.

Kingston, D. G., Lawler, D. M., and McGregor, G. R.: Linkages between atmospheric circulation, climate and streamflow in the northern North Atlantic: research prospects, Prog. Phys. Geogr., 30, 143-174, 2006.

Kulkarni, A. and von Storch, H.: Monte Carlo experiments on the effect of serial correlation on the Mann-Kendall test of trend, Meteorol. Z., 4, 82-85, 1995.

Laizé, C. L. R. and Hannah, D. M.: Modification of climate-river flow associations by basin properties, J. Hydrol., 389, 186-204, 2010.

Leahy, P. G. and Kiely, G.: Short Duration Rainfall Extremes in Ireland: Influence of Climatic Variability, Water Resour. Manage., 25, 987-1003, doi:10.1007/s11269-010-9737-2, 2011.

Lynn, M. A.: Estimating flood magnitude/return period relationships and the effect of catchment drainage, Hydrology Unit Report, Office of the Public Works, Dublin, 1981.

Madsen, H.: Automatic calibration of a conceptual rainfall-runoff model using multiple objectives, J. Hydrol., 235, 276-288, 2000.

Manley, R. E.: Simulation of flows in ungauged basins, Hydrolog. Sci. J., 23, 85-101, 1978.

Mann, H. B.: Nonparametric tests against trend, Econometrica, 13, 245-259, 1945.

Maraun, D., Osborn, T. J., and Rust, H. W.: The influence of synoptic airflow on UK daily precipitation extremes, Part I: Observed spatio-temporal relationships, Clim. Dynam., 36, 261275, doi:10.1007/s00382-009-0710-9, 2011.

Meath County Council: Navan Development Plan 2009-2015, Navan, Ireland, 2009.

Merz, B., Vorogushyn, S., Uhlemann, S., Delgado, J., and Hundecha, Y.: HESS Opinions "More efforts and scientific rigour are needed to attribute trends in flood time series", Hydrol. Earth Syst. Sci., 16, 1379-1387, doi:10.5194/hess-16-13792012, 2012.

Montanari, A., Young, G., Savenije, H. H. G., Hughes, D., Wagener, T., Ren, L. L., Koutsoyiannis, D., Cudennec, C., Toth, E., Grimaldi, S., Blöschl, G., Sivapalan, M., Beven, K., Gupta, H., Hipsey, M., Schaefli, B., Arheimer, B., Boegh, E., Schymanski, S. J., Di Baldassarre, G., Yu, B., Hubert, P., Huang, Y., Schumann, A., Post, D. A., Srinivasan, V., Harman, C.,
Thompson, S., Rogger, M., Viglione, A., McMillan, H., Characklis, G., Pang, Z., and Belyaev, V.: "Panta Rhei-Everything Flows": Change in hydrology and society - The IAHS Scientific Decade 2013-2022, Hydrolog. Sci. J., 58, 1256-1275, doi:10.1080/02626667.2013.809088, 2013.

Moriasi, D. N., Arnold, J. G., Van Liew, M. W., Binger, R. L., Harmel, R. D., and Veith, T. L.: Model evaluation guidelines for systematic quantification of accuracy in watershed simulations, T. ASABE, 50, 885-900, 2007.

Murphy, C., Fealy, R., Charlton, R., and Sweeney, J.: The reliability of an 'off-the-shelf' conceptual rainfall runoff model for use in climate impact assessment: uncertainty quantification using Latin hypercube sampling, Area, 38, 65-78, doi:10.1111/j.14754762.2006.00656.x, 2006.

Murphy, C., Bastola, S., Hall, J., Harrigan, S., Murphy, N., and Holman, C.: Against a 'wait and see' approach in adapting to climate change, Irish Geography, 44, 81-95, 2011.

Murphy, C., Harrigan, S., Hall, J., and Wilby, R. L.: Climatedriven trends in mean and high flows from a network of reference stations in Ireland, Hydrolog. Sci. J., 58, 755-772, doi:10.1080/02626667.2013.782407, 2013.

Nash, J. E. and Sutcliffe, J. V.: River Flow Forecasting through Conceptual Models Part 1 - A Discussion of Principles, J. Hydrol., 10, 282-290, 1970.

O'Kelly, J. J.: The employment of Unit Hydrographs to determine the flows of Irish arterial drainage channels, Proc. Inst. Civil Eng., 4, 365-412, 1955.

Önöz, B. and Bayazit, M.: Block bootstrap for Mann-Kendall trend test of serially dependent data, Hydrol. Process., 26, 3552-3560, doi:10.1002/hyp.8438, 2012.

OPW: Flood Studies Update, Technical research report, vol. 4, Office of Public Works (OPW), Trim, Ireland, in press, 2014.

Petrone, K. C., Hughes, J. D., Van Niel, T. G., and Silberstein, R. P.: Streamflow decline in southwestern Australia, 1950-2008, Geophys. Res. Lett., 37, L11401, doi:10.1029/2010GL043102, 2010.

Petrow, T. and Merz, B.: Trends in flood magnitude, frequency and seasonality in Germany in the period 1951-2002, J. Hydrol., 317, 129-141, 2009.

Pettitt, A. N.: A Non-Parametric Approach to the Change-Point Problem, J. Roy. Stat. Soc. C, 28, 126-135, 1979.

Platt, J. R.: Strong Inference, Science, 146, 347-353, 1964.

Raup, D. C. and Chamberlin, T. C.: The Method of Multiple Working Hypotheses, J. Geol., 103, 349-354, 1995.

Reed, S., Koren, V., Smith, M., Zhang, Z., Moreda, F., Seo, D.-J., and DMIP Participants: Overall distributed model intercomparison project results, J. Hydrol., 298, 27-60, 2004.

Schreider, S. Y., Jakeman, A. J., Letcher, R. A., Nathan, R. J., Neal, B. P., and Beavis, S. G.: Detecting changes in streamflow response to changes in non-climatic catchment conditions: Farm dam development in the Murray-Darling basin, Australia, J. Hydrol., 262, 84-98, 2002.

Seibert, J. and McDonnell, J. J.: Land-cover impacts on streamflow: a change-detection modelling approach that incorporates parameter uncertainty, Hydrolog. Sci. J., 55, 316-332, 2010.

Sen, P. K.: Estimates of the regression coefficient based on Kendall's tau, J. Am. Stat. Assoc., 63, 1379-1389, 1968.

Sivapalan, M., Savenije, H. H. G., and Blöschl, G.: Sociohydrology: A new science of people and water, Hydrol. Process., 26, 1270-1276, doi:10.1002/hyp.8426, 2012. 
Stahl, K., Hisdal, H., Hannaford, J., Tallaksen, L. M., van Lanen, H. A. J., Sauquet, E., Demuth, S., Fendekova, M., and Jódar, J.: Streamflow trends in Europe: evidence from a dataset of nearnatural catchments, Hydrol. Earth Syst. Sci., 14, 2367-2382, doi:10.5194/hess-14-2367-2010, 2010.

Theil, H.: A Rank-invariant Method of Linear and Polynomial Regression Analysis, I., Nederlands Akad. Wetensch. Proc., 53, 386-392, 1950.

Villarini, G., Serinaldi, F., Smith, J. A., and Krajewski, W. F.: On the stationarity of annual flood peaks in the continental United States during the 20th century, Water Resour. Res., 45, W08417, doi:10.1029/2008WR007645, 2009.

Villarini, G., Smith, J. A., Baeck, M. L., Vitolo, R., Stephenson, D. B., and Krajewski, W. F.: On the frequency of heavy rainfall for the Midwest of the United States, J. Hydrol., 400, 103-120, 2011a.

Villarini, G., Smith, J. A., Serinaldi, F., and Ntelekos, A. A.: Analyses of seasonal and annual maximum daily discharge records for central Europe, J. Hydrol., 399, 299-312, 2011 b.

Vorogushyn, S. and Merz, B.: Flood trends along the Rhine: the role of river training, Hydrol. Earth Syst. Sci., 17, 3871-3884, doi:10.5194/hess-17-3871-2013, 2013.
Wilby, R. L.: Uncertainty in water resource model parameters used for climate change impact assessment, Hydrol. Process., 19, 3201-3219, doi:10.1002/hyp.5819, 2005.

Wilby, R. L., O'Hare, G., and Barnsley, N.: The North Atlantic Oscillation and British Isles climate variability, 1865-1996, Weather, 52, 266-276, doi:10.1002/j.14778696.1997.tb06323.x, 1997.

Wilcock, D. and Wilcock, F.: Modelling the hydrological impacts of channelization on streamflow characteristics in a Northern Ireland catchment, in: Modelling and Management of Sustainable Basin-Scale Water Resource Systems, IAHS Publ., 231, 41-48, 1995.

Yue, S., Pilon, P., Phinney, B., and Cavadias, G.: The influence of autocorrelation on the ability to detect trend in hydrological series, Hydrol. Process., 16, 1807-1829, 2002.

Zhang, S., Lu, X. X., Higgitt, D. L., Chen, C.-T. A., Han, J., and Sun, H.: Recent changes of water discharge and sediment load in the Zhujiang (Pearl River) Basin, China, Global Planet. Change, 60, 365-380, 2008. 